\title{
Proton/electron temperature ratio in the magnetotail
}

\author{
A. V. Artemyev ${ }^{1}$, W. Baumjohann ${ }^{2}$, A. A. Petrukovich ${ }^{1}$, R. Nakamura ${ }^{2}$, I. Dandouras ${ }^{3,4}$, and A. Fazakerley ${ }^{5}$ \\ ${ }^{1}$ Space Research Institute, Russian Academy of Sciences, Moscow, Russia \\ ${ }^{2}$ Space Research Institute, Austrian Academy of Sciences, Graz, Austria \\ ${ }^{3}$ IRAP, University of Toulouse, UPS-OMP, Toulouse, France \\ ${ }^{4}$ CNRS, IRAP, 9 Ave. Colonel Roche, BP 44346, 31028 Toulouse cedex 4, France \\ ${ }^{5}$ Mullard Space Science Laboratory, London, UK
}

Received: 30 September 2011 - Revised: 10 December 2011 - Accepted: 12 December 2011 - Published: 15 December 2011

\begin{abstract}
We study the temperature ratio of protons and electrons based on statistics of Cluster observations in the Earth's magnetotail from 2001 to 2004. During these years, from June to November, the Cluster spacecraft visited the plasma sheet at the distance $r \sim-19 R_{\mathrm{E}}$. We use proton and electron moments collected in the central region of the plasma sheet $\left(|Z|<5 R_{\mathrm{E}}\right)$. We find an average ratio of proton and electron temperatures $\left\langle T_{\mathrm{p}} / T_{\mathrm{e}}\right\rangle \approx 3.5$. The dependence of $T_{\mathrm{p}}$ on $T_{\mathrm{e}}$ can be approximated by the power-law function: $T_{\mathrm{p}} \approx 11 T_{\mathrm{e}}^{0.62}$, where $T_{\mathrm{p}}$ and $T_{\mathrm{e}}$ are measured in MK. A previous reported ratio $\left\langle T_{\mathrm{p}} / T_{\mathrm{e}}\right\rangle \sim 7$ is limited to small electron temperatures $<20 \mathrm{MK}$. The observations with the high electron temperature correspond to smaller values of the electron density and larger values of the proton and electron bulk velocities. A correlation between $T_{\mathrm{e}}$ and curlometer current density is not found.
\end{abstract}

Keywords. Magnetospheric physics (Magnetotail; Plasma convection; Plasma sheet)

\section{Introduction}

The proton and electron temperature ratio $T_{\mathrm{p}} / T_{\mathrm{e}}$ in the Earth magnetotail is controlled by the relationship between various mechanisms of acceleration (and thermalization) of solar wind and ionospheric plasma. Thus, this ratio is important for understanding of the general energy transport in the magnetosphere.

Baumjohann et al. (1989) estimated this ratio as $\left\langle T_{\mathrm{p}} / T_{\mathrm{e}}\right\rangle \approx$ 7. The authors showed that the proton temperature grows linearly with the electron one. This result was obtained with data collected by the AMPTE/IRM spacecraft. Statistics included only observations with the maximum $T_{\mathrm{e}} \leq 10 \mathrm{MK}$.

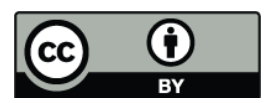

Correspondence to: A. V. Artemyev (ante0226@yandex.ru)
Kaufmann et al. (2005) obtained $\left\langle T_{\mathrm{p}} / T_{\mathrm{e}}\right\rangle \approx 6-8$ using eight years of Geotail observations with approximately the same maximum $T_{\mathrm{e}}$.

We use Cluster data for a similar analysis and in particular demonstrate how the ratio $\left\langle T_{\mathrm{p}} / T_{\mathrm{e}}\right\rangle$ changes with taking into account electrons with temperature $T_{\mathrm{e}}>10 \mathrm{MK}$.

\section{Cluster observation}

In this paper we use data collected by the Cluster mission during 2001-2004. We include in our statistics time intervals when the spacecraft visited the plasma sheet (from June to November): $X<-12 R_{\mathrm{E}},|Y|<15 R_{\mathrm{E}},|Z|<5 R_{\mathrm{E}}$. We use proton moments from CIS/CODIF (Rème et al., 2001), electron moments from PEACE (Johnstone et al., 1997) and magnetic field from FGM (Balogh et al., 2001). The additional criteria for our statistics are: a small value of the magnetic field $\left|B_{\mathrm{x}}\right|<15 \mathrm{nT}$ (only the central region of the plasma sheet is considered), a small value of the electron density $n_{\mathrm{e}}<1.5 \mathrm{~cm}^{-3}$ (to exclude observations of the plasma sheet at the distant flanks) and a small difference between proton and electron densities $\left(n_{\mathrm{e}}-n_{\mathrm{p}}\right) /\left(n_{\mathrm{e}}+n_{\mathrm{p}}\right)<0.1$. The distribution of points from our statistics in space domain is presented in Fig. 1. All data are obtained from the Cluster Active Archive. We use the GSM coordinate system.

We collect two statistics of plasma parameters in the plasma sheet. The first statistics (32 700 points) corresponds to observations by only the $\mathrm{C} 1$ spacecraft. The second statistics (211 800 points) corresponds to observations of electrons by $\mathrm{C} 2$ and observations of protons by $\mathrm{C} 1$ and $\mathrm{C} 4$ (we use $\mathrm{C} 4$ for 2001-2003 and $\mathrm{C} 1$ for 2004). In the last case we interpolate proton moments to a common time scale with that of electrons and use the magnetic field profile to obtain proton moment values in the points with the same value of $B_{\mathrm{x}}$ as electron moments. Although in the second statistics data from different observational points are used, this analysis has

Published by Copernicus Publications on behalf of the European Geosciences Union. 

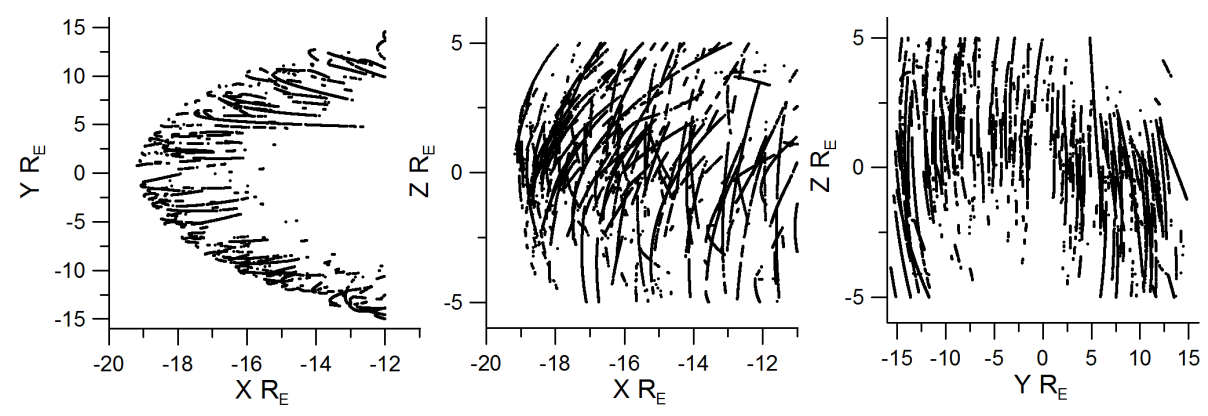

Fig. 1. Distribution of points of observation in the space.

an advantage of seven times more samples. Thus we mainly use it, while the first statistics is important to recheck our conclusions with same point measurements.

We use only the CODIF instrument because it has a larger energy range in comparison with HIA. This effect could be important in case of the large temperature $T_{\mathrm{p}}$ (this is a relatively typical situation for the central region of the plasma sheet, where the thin current sheet with the hot proton population can be found, (see, e.g. Artemyev et al., 2009)).

For both statistics we plot values of the proton temperature $T_{\mathrm{p}}$ versus the electron temperature $T_{\mathrm{e}}$ (Fig. 2, top panels). We calculate current density with the help of the curlometer technique (Dunlop et al., 1988): $j_{\mathrm{yz}}=\sqrt{j_{\mathrm{y}}^{2}+j_{\mathrm{z}}^{2}}$. We obtain the average values of proton and electron bulk velocities $v=\sqrt{v_{\mathrm{x}}^{2}+v_{\mathrm{y}}^{2}}$, current density $j_{\mathrm{yz}}$ and density $n_{\mathrm{e}}$ for thirteen intervals of $T_{\mathrm{e}}$ values: $\left(T_{\mathrm{e}}\right)_{k}=(5 k \pm 5) \mathrm{MK}, k=1 . .12$ and $\left(T_{\mathrm{e}}\right)_{0}=(2.5 \pm 2.5) \mathrm{MK}$, see Fig. 2. Electron and proton temperatures are generally correlated, but the dependence of $T_{\mathrm{e}}$ on $T_{\mathrm{p}}$ is not linear. Observations with larger $T_{\mathrm{e}}$ relates to smaller values of $n_{\mathrm{e}}$ and to more active conditions (larger $v)$. However, value of $j_{\mathrm{yz}}$ does not depends on $T_{\mathrm{e}}$ : the increase of electron temperature is not related directly to thin current sheets (or to other sharp spatial gradients of magnetic field) with large $j_{\mathrm{yz}}$. These results are similar for both statistics. The number of points decrease with increase of $T_{\mathrm{e}}$ : for $T_{\mathrm{e}}<20 \mathrm{MK}$ we have $N \sim 9000$ and $N \sim 30000$ for the first and second statistics, and for $T_{\mathrm{e}}>40 \mathrm{MK}$ we have $N<300$ and $N<8000$, correspondingly. Due to the small value of $N$ for large $T_{\mathrm{e}}$ in the first statistics (when only data from $\mathrm{C} 1$ are used) we take into account the second statistics and obtain the same behavior of the main parameters.

The average ratio is $\left\langle T_{\mathrm{p}} / T_{\mathrm{e}}\right\rangle \approx 3.5$. This value is substantially smaller than that obtained by Baumjohann et al. (1989) and by Kaufmann et al. (2005), i.e. $\left\langle T_{\mathrm{p}} / T_{\mathrm{e}}\right\rangle \approx 7$, but agrees with results of a recent statistics of observations of thin current sheets by the Cluster mission (Artemyev et al., 2011a).

We approximate the dependence of $T_{\mathrm{p}}$ on $T_{\mathrm{e}}$ by the powerlaw function: $T_{\mathrm{p}}=C T_{\mathrm{e}}^{\sigma}\left(T_{\mathrm{p}}\right.$ and $T_{\mathrm{e}}$ are measured in $\left.\mathrm{MK}\right)$. For both statistics we obtain $C \approx 11$ and $\sigma \approx 0.62$ by the least square method. Corresponding grey curves are shown in the top panels of Fig. 2. The variation of $C$ and $\sigma$ by $\pm 15 \%$ allows to describe more than $85 \%$ of observations.

We consider the dependence of the coefficients $C$ and $\sigma$ on $Y$ coordinate and $B_{\mathrm{x}}$. We divide the whole dataset into the three ranges $\left(\left|B_{\mathrm{x}}\right|<5 \mathrm{nT}, 5 \mathrm{nT}<\left|B_{\mathrm{X}}\right|<10 \mathrm{nT}\right.$ and $\left.10 \mathrm{nT}<\left|B_{\mathrm{X}}\right|<15 \mathrm{nT}\right)$ and the values of $C$ and $\sigma$ are equal with the $10 \%$ accuracy. The same is true for four ranges of $Y$ coordinates $\left(-15 R_{\mathrm{E}}<Y<-10 R_{\mathrm{E}},-10 R_{\mathrm{E}}<Y<-5 R_{\mathrm{E}}\right.$, $-5 R_{\mathrm{E}}<Y<5 R_{\mathrm{E}}, 5 R_{\mathrm{E}}<Y<10 R_{\mathrm{E}}$ and $10 R_{\mathrm{E}}<Y<$ $\left.15 R_{\mathrm{E}}\right)$. Therefore, the empirical law $T_{\mathrm{p}}=11 T_{\mathrm{e}}^{0.62}$ could be considered as universal for the central region of the plasma sheet. The previous result $T_{\mathrm{p}} \sim 7 T_{\mathrm{e}}$ (Baumjohann et al., 1989) can be obtained in our statistics for $T_{\mathrm{e}}<10 \mathrm{MK}$. One can write $T_{\mathrm{p}}=\left(C T_{\mathrm{e}}^{\sigma-1}\right) T_{\mathrm{e}} \approx \tilde{C} T_{\mathrm{e}}$ and estimate coefficient $\tilde{C}$ as

$\tilde{C}=C\left\langle T_{\mathrm{e}}^{\sigma-1}\right\rangle=C\left(\frac{1}{10} \int_{0}^{10} x^{\sigma-1} d x\right) \approx 7.4$

The nonlinear dependence of $T_{\mathrm{p}}$ on $T_{\mathrm{e}}$ points out to the existence of several independent mechanisms of solar wind and ionospheric particles acceleration. To demonstrate this effect we plot ratio $T_{\mathrm{p}} / T_{\mathrm{e}}$ as a function of $T_{\mathrm{e}}$ and $T_{\mathrm{p}}$ (Fig. 3). For every value of $T_{\mathrm{e}}>10 \mathrm{MK}$ one can find protons with temperature $T_{\mathrm{p}} \sim 3 T_{\mathrm{e}}$. Also ratio $T_{\mathrm{p}} / T_{\mathrm{e}} \approx 3$ can be observed for almost all possible proton temperatures. The ratio $T_{\mathrm{p}} / T_{\mathrm{e}} \approx 5-7$ corresponds to relatively cold electrons with $T_{\mathrm{e}}<20 \mathrm{MK}$ in agreement with Baumjohann et al. (1989). However, this ratio can be observed for a wide range of $T_{\mathrm{p}}$.

The three main mechanisms are responsible for the acceleration of cold solar wind and ionospheric particles up to tens MK: (1) acceleration in the distant X-line (e.g. AshourAbdalla et al., 1996, and references therein), (2) adiabatic particle heating during earthward convection (e.g. Lyons, 1984; Artemyev et al., 2011b, and references therein) and (3) nonadiabatic proton acceleration in the vicinity of the neutral sheet by the dawn-dusk electrostatic field (e.g. Lyons and Speiser, 1982; Ashour-Abdalla et al., 1993, and references therein). The combination of these mechanisms is capable to provide the formation of the both populations with $T_{\mathrm{p}} / T_{\mathrm{e}} \sim 3$ and $T_{\mathrm{p}} / T_{\mathrm{e}} \sim 7$. 

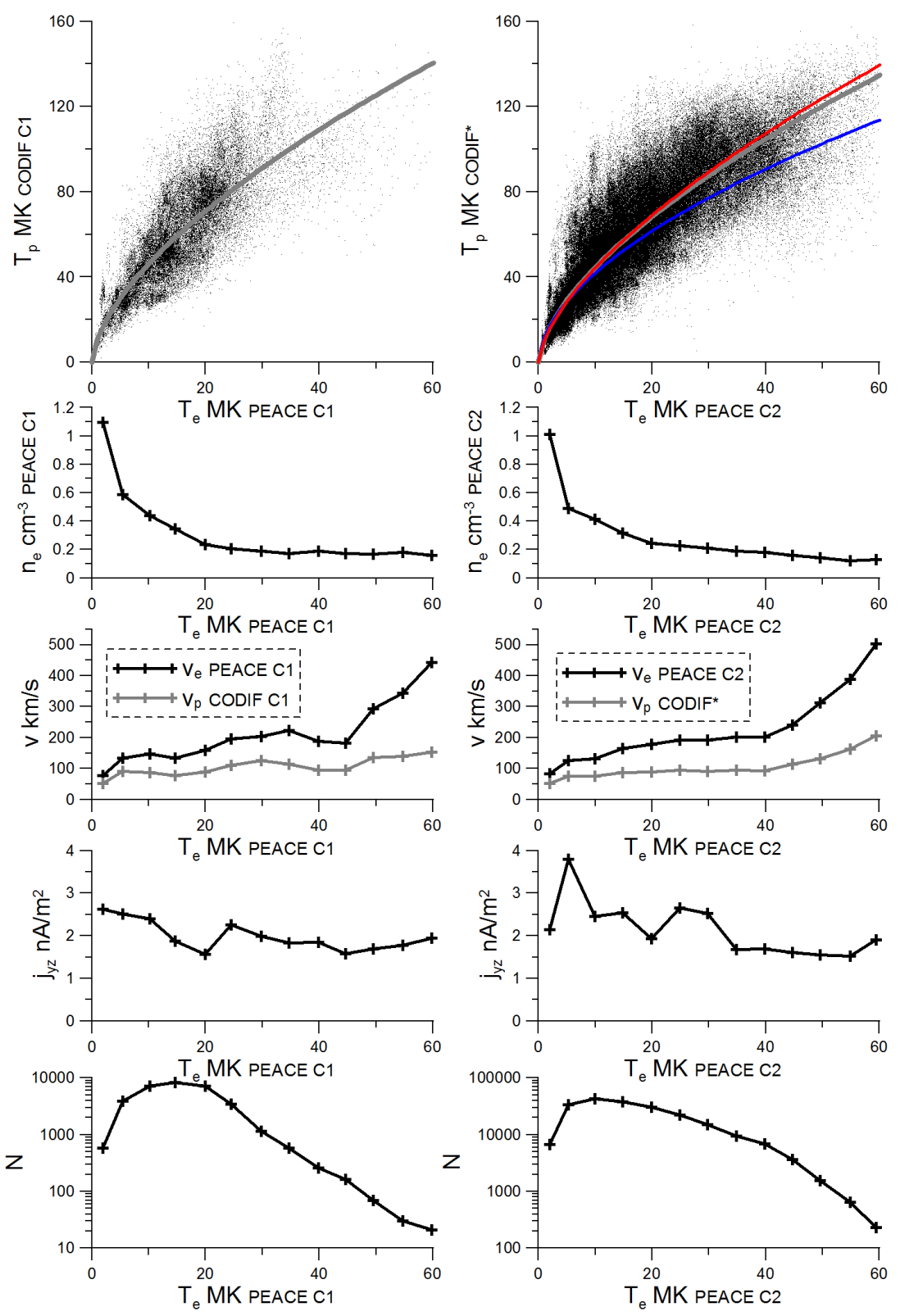

Fig. 2. Top panels: proton temperature $T_{\mathrm{p}}$ versus electron temperature $T_{\mathrm{e}}$ for both statistics described in text (CODIF*: data from C4 for 2001-2003 and data from $\mathrm{C} 1$ for 2004). Also the approximations $T_{\mathrm{p}}=C T_{\mathrm{e}}^{\sigma}$ are shown (see text for details). Middle panels: averaged value of electron density $n_{\mathrm{e}}$, electron and proton bulk velocities $v_{\mathrm{e}}$ and $v_{\mathrm{p}}$ and curlometer current density $j_{\mathrm{zy}}$ as functions of $T_{\mathrm{e}}$. Bottom panels: number of points in statistics for corresponding value of $T_{\mathrm{e}}$.

The observed $T_{\mathrm{p}} / T_{\mathrm{e}}$ ratio also could correspond to various conditions in the solar wind. For wide a statistics of observations in the magnetosheath the ratio $T_{\mathrm{p}} / T_{\mathrm{e}} \sim 7-12$ was reported by Phan et al. (1994). However, specific conditions in the solar wind could provide $T_{\mathrm{p}} / T_{\mathrm{e}} \sim 3$ (Lavraud et al., 2009). For these ratios to be decreased (or, at least, preserved) in the magnetotail electrons should be accelerated more effective (or by the same rate) than protons. The preferred electron acceleration could correspond to mag- netic reconnection or to various transient processes (see, e.g. Ashour-Abdalla et al., 2011, and references therein). The same rate of the electron and proton acceleration is predicted in the model of adiabatic (electrons) and quasi-adiabatic (protons) particle heating during earthward convection (e.g. Zelenyi et al., 1990, and references therein).

To obtain our approximation $T_{\mathrm{p}}=C T_{\mathrm{e}}^{\sigma}$ we use all available data of plasma moments collected in the central region magnetotail. However, there are several instrument issues 

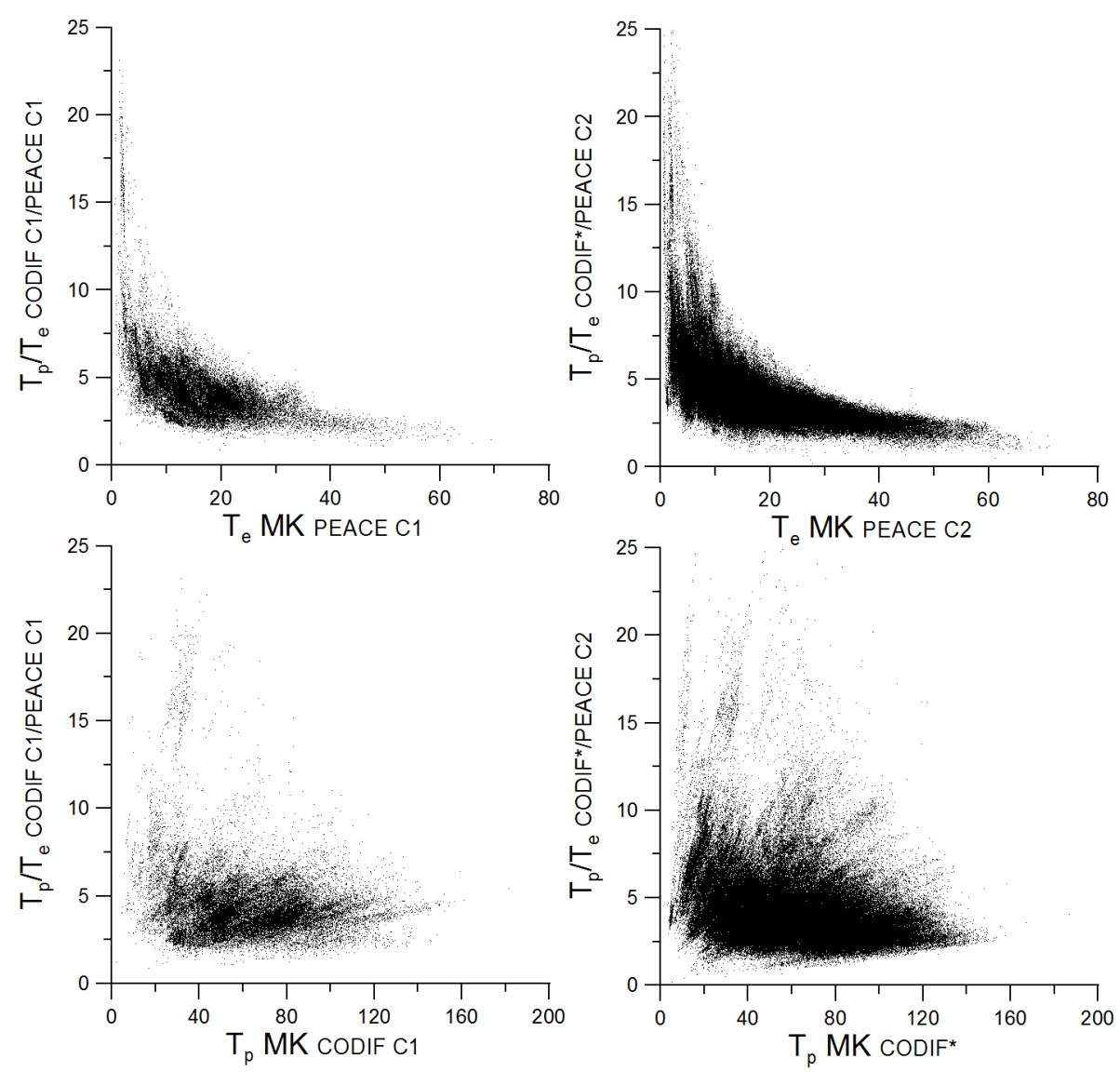

Fig. 3. Ratio $T_{\mathrm{p}} / T_{\mathrm{e}}$ as functions of $T_{\mathrm{e}}$ and $T_{\mathrm{p}}$ for both statistics described in text.

which might affect the statistics. Points with relatively high $T_{\mathrm{p}}$ could be with underestimation of proton temperature due to the limited energy range of CODIF instrument. Points with small $n_{\mathrm{e}}$ could be subject to underestimation of electron temperature due to photoelectrons. To moderate these possible problems we make tests with the following two selection criteria: only moderate proton temperature $\left(T_{\mathrm{p}}<70 \mathrm{MK}\right)$ and only larger densities $\left(n_{\mathrm{e}}>0.2 \mathrm{~cm}^{-3}\right)$ are taken into account. The resulted approximations are shown in right top panel of Fig. 2 (red curve corresponds to $n_{\mathrm{e}}>0.2 \mathrm{~cm}^{-3}$ and blue curve corresponds to $T_{\mathrm{p}}<70 \mathrm{MK}$ ) and obtained coefficients are $C=11.5, \sigma=0.56$ (for $T_{\mathrm{p}}<70 \mathrm{MK}$ ) and $C=10$, $\sigma=0.64$ (for $n_{\mathrm{e}}>0.2 \mathrm{~cm}^{-3}$ ). Therefore, we can conclude that the possible photoelectron and larger $T_{\mathrm{p}}$ effects do not influence on our main result.

\section{Conclusions}

We demonstrate that the relation between proton and electron temperatures in the plasma sheet around $r \sim-19 R_{\mathrm{E}}$ can be approximated by the expression $T_{\mathrm{p}}=11 T_{\mathrm{e}}^{0.62}$, where $T_{\mathrm{p}}$ and $T_{\mathrm{e}}$ are measured in MK. The ratio $T_{\mathrm{p}} / T_{\mathrm{e}} \approx 5-7$ corresponds to the cold electron population $\left(T_{\mathrm{e}}<10 \mathrm{MK}\right)$ in agreement with Baumjohann et al. (1989). We discover that a ratio $T_{\mathrm{p}} / T_{\mathrm{e}} \approx 3$ can be observed for a wide range of $T_{\mathrm{e}}$ and $T_{\mathrm{p}}$.

Acknowledgements. A.V.A. is grateful to L. M. Zelenyi for fruitful discussions and to A. Walsh for useful suggestions and comments. Authors would like to acknowledge Cluster Active Archive (http://caa.estec.esa.int) and the Cluster instrument teams FGM, PEACE and CIS for excellent data. Work of A.V.A. and A.A.P. was supported by the RFBR (projects 10-05-91001, 10-02-93114). The work of R.N. was supported by Austrian Science Fund (FWF) I429-N16. A.V.A. would like to acknowledge hospitality of IWF, Graz, Austria.

Topical Editor I. A. Daglis thanks one anonymous referee for her/his help in evaluating this paper.

\section{References}

Artemyev, A. V., Petrukovich, A. A., Zelenyi, L. M., Nakamura, R., Malova, H. V., and Popov, V. Y.: Thin embedded current sheets: Cluster observations of ion kinetic structure and analytical models, Ann. Geophys., 27, 4075-4087, doi:10.5194/angeo27-4075-2009, 2009.

Artemyev, A. V., Petrukovich, A. A., Nakamura, R., and Zelenyi, L. M.: Cluster statistics of thin current sheets in the Earth magnetotail: specifics of the dawn flank, proton temperature pro- 
files and electrostatic effects., J. Geophys. Res., 116, A09233, doi:10.1029/2011JA016801, 2011a.

Artemyev, A. V., Zelenyi, L. M., Petrukovich, A. A., and Nakamura, R.: Hot electrons as tracers of large-scale structure of magnetotail current sheets, Geophys. Res. Lett., 38, L14102, doi:10.1029/2011GL047979, 2011b.

Ashour-Abdalla, M., Berchem, J. P., Buechner, J., and Zelenyi, L. M.: Shaping of the magnetotail from the mantle - Global and local structuring, J. Geophys. Res., 98, 5651-5676, doi:10.1029/92JA01662, 1993.

Ashour-Abdalla, M., Frank, L. A., Paterson, W. R., Peroomian, V., and Zelenyi, L. M.: Proton velocity distributions in the magnetotail: Theory and observations, J. Geophys. Res., 101, 25872598, doi:10.1029/95JA02539, 1996.

Ashour-Abdalla, M., El-Alaoui, M., Goldstein, M. L., Zhou, M., Schriver, D., Richard, R., Walker, R., Kivelson, M. G., and Hwang, K.-J.: Observations and simulations of non-local acceleration of electrons in magnetotail magnetic reconnection events, Nature Physics, 7, 360-365, doi:10.1038/nphys1903, 2011.

Balogh, A., Carr, C. M., Acuña, M. H., Dunlop, M. W., Beek, T. J., Brown, P., Fornacon, K.-H., Georgescu, E., Glassmeier, K.H., Harris, J., Musmann, G., Oddy, T., and Schwingenschuh, K.: The Cluster Magnetic Field Investigation: overview of in-flight performance and initial results, Ann. Geophys., 19, 1207-1217, doi:10.5194/angeo-19-1207-2001, 2001.

Baumjohann, W., Paschmann, G., and Cattell, C. A.: Average plasma properties in the central plasma sheet, J. Geophys. Res., 94, 6597-6606, doi:10.1029/JA094iA06p06597, 1989.

Dunlop, M. W., Southwood, D. J., Glassmeier, K.-H., and Neubauer, F. M.: Analysis of multipoint magnetometer data, Adv. Space Res., 8, 273-277, doi:10.1016/0273-1177(88)90141X, 1988.

Johnstone, A. D., Alsop, C., Burge, S., Carter, P. J., Coates, A. J., Coker, A. J., Fazakerley, A. N., Grande, M., Gowen, R. A., Gurgiolo, C., Hancock, B. K., Narheim, B., Preece, A., Sheather, P. H., Winningham, J. D., Woodliffe, R. D., Johnstone, A. D., Alsop, C., Burge, S., Carter, P. J., Coates, A. J., Coker, A. J., Fazakerley, A. N., Grande, M., Gowen, R. A., Gurgiolo, C., Hancock, B. K., Narheim, B., Preece, A., Sheather, P. H., Winningham, J. D., and Woodliffe, R. D.: Peace: a Plasma Electron and Current Experiment, Space Sci. Rev., 79, 351-398, doi:10.1023/A:1004938001388, 1997.

Kaufmann, R. L., Paterson, W. R., and Frank, L. A.: Relationships between the ion flow speed, magnetic flux transport rate, and other plasma sheet parameters, J. Geophys. Res., 110, A09216, doi:10.1029/2005JA011068, 2005.
Lavraud, B., Borovsky, J. E., Génot, V., Schwartz, S. J., Birn, J., Fazakerley, A. N., Dunlop, M. W., Taylor, M. G. G. T., Hasegawa, H., Rouillard, A. P., Berchem, J., Bogdanova, Y., Constantinescu, D., Dandouras, I., Eastwood, J. P., Escoubet, C. P., Frey, H., Jacquey, C., Panov, E., Pu, Z. Y., Shen, C., Shi, J., Sibeck, D. G., Volwerk, M., and Wild, J. A.: Tracing solar wind plasma entry into the magnetosphere using ion-toelectron temperature ratio, Geophys. Res. Lett., 36, L18109, doi:10.1029/2009GL039442, 2009.

Lyons, L. R.: Electron energization in the geomagnetic tail current sheet, J. Geophys. Res., 89, 5479-5487, doi:10.1029/JA089iA07p05479, 1984.

Lyons, L. R. and Speiser, T. W.: Evidence for current sheet acceleration in the geomagnetic tail, J. Geophys. Res., 87, 2276-2286, doi:10.1029/JA087iA04p02276, 1982.

Phan, T.-D., Paschmann, G., Baumjohann, W., Sckopke, N., and Luehr, H.: The magnetosheath region adjacent to the dayside magnetopause: AMPTE/IRM observations, J. Geophys. Res., 99, 121-141, doi:10.1029/93JA02444, 1994.

Rème, H., Aoustin, C., Bosqued, J. M., Dandouras, I., Lavraud, B., Sauvaud, J. A., Barthe, A., Bouyssou, J., Camus, Th., CoeurJoly, O., Cros, A., Cuvilo, J., Ducay, F., Garbarowitz, Y., Medale, J. L., Penou, E., Perrier, H., Romefort, D., Rouzaud, J., Vallat, C., Alcaydé, D., Jacquey, C., Mazelle, C., d’Uston, C., Möbius, E., Kistler, L. M., Crocker, K., Granoff, M., Mouikis, C., Popecki, M., Vosbury, M., Klecker, B., Hovestadt, D., Kucharek, H., Kuenneth, E., Paschmann, G., Scholer, M., Sckopke, N., Seidenschwang, E., Carlson, C. W., Curtis, D. W., Ingraham, C., Lin, R. P., McFadden, J. P., Parks, G. K., Phan, T., Formisano, V., Amata, E., Bavassano-Cattaneo, M. B., Baldetti, P., Bruno, R., Chionchio, G., Di Lellis, A., Marcucci, M. F., Pallocchia, G., Korth, A., Daly, P. W., Graeve, B., Rosenbauer, H., Vasyliunas, V., McCarthy, M., Wilber, M., Eliasson, L., Lundin, R., Olsen, S., Shelley, E. G., Fuselier, S., Ghielmetti, A. G., Lennartsson, W., Escoubet, C. P., Balsiger, H., Friedel, R., Cao, J.-B., Kovrazhkin, R. A., Papamastorakis, I., Pellat, R., Scudder, J., and Sonnerup, B.: First multispacecraft ion measurements in and near the Earth's magnetosphere with the identical Cluster ion spectrometry (CIS) experiment, Ann. Geophys., 19, 1303-1354, doi:10.5194/angeo19-1303-2001, 2001.

Zelenyi, L. M., Zogin, D. V., and Büchner, J.: Quasiadiabatic dynamics of charged particles in the tail of the magnetosphere, Cosmic Research, 28, 369-380, 1990. 